\title{
LESSONS LEARNED FROM MCMASTER'S FIRST CRACK AT A SUSTAINABILITY COURSE
}

\author{
Joel Hilchey and Mallory Drumm \\ McMaster University \\ hilchejm@mcmaster.ca
}

\begin{abstract}
While many courses at McMaster University cover some sustainability related material, 2012 saw the initiation of a new special project: To develop and deliver McMaster's first dedicated sustainability course, complete with community involvement, project-based learning, and registration open to students across all faculties.

Five areas are discussed where we've seen huge opportunity for innovation in higher education: avenues for community involvement, cross-faculty enrollment, innovative teaching formats, project-based learning (both in terms of project success rates and benefits to students), and learning objectives (specifically as developed for sustainability education).
\end{abstract}

Keywords: Sustainability Education, Course Design, Community Involvement, Interdisciplinary Education.

\section{INTRODUCTION}

SUSTAIN 2 A03 - The Sustainable Future Project (SFP) was initiated as a special project of the Engineering Faculty in early 2012. A planning team was formed including representatives from five faculties, McMaster's Office of Sustainability, and the Centre for Leadership in Learning. Joel Hilchey was hired as the course designer and instructor, Mallory Drumm as the SFP Manager, and the first run of the course was held in the winter term, 2013 with 84 students enrolled.

This paper is meant to serve as a record of an ongoing discussion of lessons learned during this course prototype, and has two main outcome goals: First, to improve the existing course model and solicit feedback for potential adjustments in year two, and; second, to create dialogue and frameworks that might be used to improve existing courses or streamline the creation of other new ones.

It is hoped that this will be the start of a conversation that will highlight successes, share newly developing best practices, and equip all readers with more skills to deliver sustainability education and make higher education more sustainable in nature.

\section{AVENUES FOR COMMUNITY INVOLVEMENT}

One of the goals of the course had been to provide students opportunities to integrate with community members, ideally providing mutually beneficial relationships. In the first run of the course, there were two streams of students, some doing Community Supported Projects, and others doing Self-Generated Projects.

\subsection{Community Supported Projects}

2.1.1 Getting Community-Supported Project Proposals. We sought community project champions to propose specific ideas for student projects. This was largely led by Kate Whalen, Senior Manager of University Sustainability, and supported by the planning team of professors. We got a great response from the network of people within the university, but only a few of the fifteen projects were proposed by people or organizations external to McMaster. The response seems to be largely related to personal connections.

2.1.2 Students Working with Community Project Champions. The community members committed to supporting students through the projects, and the initial ideas and requirements were fleshed out ahead of the course time to maximize students' ability to accomplish the tasks. The students ranked their project choices and once they were assigned a project, they met with their project champion. The project champions were instructed to be open with the project specifics in order to facilitate student buy-in and ownership. This had varying degrees of success, with some students feeling entirely in control, while others felt the project was too constrictive to allow as much real input as they wanted. 
2.1.3 Project Champions working with Students. Project champions themselves reported that they struggled with this of input and control balance also, with one claiming that "even as she pushed for students to make decisions, they constantly defaulted to her for the answers." Another said, "the group seemed unable to overcome the magnetism of the original idea proposed by the project champion, and just couldn't seem to take ownership of it." On the other hand, one project champion described how her "group took an idea and ran with it, which was important for their learning, but the product didn't end up being as useful to accomplish the original goals."

2.1.4 Scalability. We also found that working with Community Project Champions and setting up projects was resource intensive. It took a part time manager to arrange project ideas and ensure there were 15 project ideas available for students. This would serve a tutorial of up to 60 people. To scale this idea would consistently require finding new project ideas and new project champions, each time helping to set up proposals, not to mention managing the interests of multiple community organizations and the reputation of the university. In reality, this would become easier over time, but it will still be resource intensive, making scaling the course a challenge.

\subsection{Community Mentors}

In the stream of self-generated projects, the community involvement component consisted of involving mentors and stakeholders to help students throughout the process as they created their own ideas from scratch.

2.2.1 Getting Community Mentors. As with Project Champions, the community members who signed up as mentors were almost all approached individually and had a relationship with the course or university. People were, in general, quite willing to sign up on an ad hoc, "if I can help out, I will," basis, rather than in a specific project champion role. They did wonder, however, what specific role they could play. A number of mentors were still McMaster students, showing that students wanted to be involved in other ways, even if they weren't registered in the course.

2.2.2 Working with Community Mentors. Mentors were offered a few specific tutorial sessions where they could participate in "mastermind" sessions to help students refine their project ideas. They proved very useful in this capacity, seeming to offer a level of life experience that added wisdom. The challenge, however, was that these sessions were during the day, and some mentors were unavailable. While the mentors were invited to attend lectures also, none of them did. While the names existed on an online list, it seems students were unlikely to reach out to people unless they had met in person.

2.2.3 Community Stakeholders. All students had the assignment of finding community stakeholders and interviewing them for feedback on their project ideas. Overall, students seemed to get value from the processes of reaching out and consulting with people. This is an important skill, and something that we hope can be leveraged to future involvement.

\section{CROSS FACULTY ENROLLMENT}

The course, although offered and administrated by the Faculty of Engineering, was unique in that its enrollment was capped by faculty, ensuring a cross-section of the entire university.

\subsection{Small Group Discussion}

Students regularly commented in their reflections that this mix of students was beneficial for them, and exposed them to ideas and arguments that were framed very differently than those to which they were accustomed. Often these ideas came out during large class discussions. In our class of 84 , these discussions were possible, but a few dominant students quickly emerged. As a result, we learned there needed to be more time allocated for smaller group discussion so these views could be explored. Additionally, some students found that perceptions of the tensions between faculties were inaccurate, and we believe that devoting more time to exploring those differences would be a benefit to everyone.

\section{2. "Anchor" Content}

Another challenge related to this cross-faculty enrollment was the lack of "anchor" content to unite the class. While readings were assigned, people didn't do them, and while there was lots of material covered, there was no clear "content list" from day one, so it seemed difficult for people to find common ground from which to explore their differences. This can be remedied in the future by incentivizing readings and by including a more explicit content list in the form of a "pre-test" or discussion questions.

\section{INNOVATIVE TEACHING FORMATS}

The course was intended to explore some alternative teaching methods, rather than the traditional lecture and 
readings. We included projects, videos, guest lecturers, class discussions, group activities, debates, and case studies.

\subsection{When Self-Directed Learning Fails}

In general, the mix of content delivery styles was well received and appreciated. However, because there were no specific incentives to do the textbook readings, almost nobody actually did them. This was peculiar, as students claimed they wanted to go deeper with the content, but admitted freely that they didn't do the readings, which would have provided that extra depth. This perhaps illustrates a larger question related to alternative teaching models: As students are given more discretion and freedom of how to use their time, and more responsibility to learn content at home while solving problems in class, a question of uncertainty still remains around whether students WILL actually take the initiative to learn the required content. Likely, this points to the need for even more meaningful evaluations. Students claimed they would have done more of the readings if there was some incentive, but noted that a specific discussion would be enough - the incentive need not be tied to an evaluation.

\section{PROJECT BASED LEARNING}

\subsection{Balancing Empowerment with Monitoring}

There were some students who procrastinated enough that they didn't make any significant progress. While it's somewhat expected that students' initial ideas will be too large or ambitious to accomplish in the one semester timeframe, it was hoped that students would realize the unreachable nature of their goals early so they could scale back the goals appropriately. Despite regular weekly check-ins with teaching assistants, some students failed to make sufficient effort early enough to re-calibrate, and ended up feeling overwhelmed near the end of their projects. To remedy this, I think it's important to add additional evaluation points midway through the project timeframe. This should provide additional incentive for students to start early, make more progress early in the term, and provide a few better opportunities for feedback.

It should be noted, however, that part of the benefit of project based learning is that students are free to fail and feel the effects of their action or inaction. So long as the opportunity for reflection is included, students should be able to learn from their experiences, and even if that experience includes feeling overwhelmed, underprepared, or unsuccessful, the identification of those feelings and the related learning is paramount. In other words, it's the ownership, not the successful execution that leads to the learning. For this reason, if too much of the process is guided, dictated, or even incentivized, it may actually detract from the students' experience. So, in our experience, we believe there was not enough guidance for the self-generated projects, but too much guidance for the community supported projects. We got feedback saying the distribution of guidance was a little bit skewed, with there being too much guidance later in the process. Therefore, frontloading seems like the way to go, with a few sporadic evaluated check-ins, and regular mentoring contact.

\section{LEARNING OBJECTIVES FOR SUSTAINABILITY EDUCATION}

\subsection{Knowledge - Sustainability Foundations}

In an introductory course, of the challenges was the wide level of background knowledge that students had. Providing opportunities for students to customize content was important, but as discussed earlier, the first iteration of the course probably provided too much flexibility and not enough "core". We opted to cover content including: sustainability lenses (sustainability as viewed from different fields and backgrounds), life cycle analysis, food, business, energy, nature, climate change, and personal sustainability actions. We also built in some flexibility for student-generated content and discussions around making projects happen. In general, this mix was well received and on-target for a first sustainability course.

\subsection{Skills - Making Change}

The course vision statement was: "Fundamentally, this course aims to promote continuing action towards a sustainable future by creating more knowledgeable and more effective change agents."

Students actually responded well to this idea, with the exception of the word "change agents". Some students preferred the term "activists", while other did NOT connect with "activist". Finding language to capture exactly what was involved in "project doing" was more challenging that expected.

\subsection{Intended Learning Outcomes}

As overall learning objectives, we decided to synthesize priorities from other research on skills for sustainability workers:

- Systemic Thinking - Understanding complexities and connections

- Critical Thinking \& Reflection - Identifying challenges with the status quo 
- Envisioning - Identifying opportunities for change and improvement

- Problem Solving - Developing specific projects

- Strategic Planning - Developing a plan for implementation

- Project Management - Implementing and adapting to unexpected changes

- Creativity, Communication \& Collaboration Engaging stakeholders

Students seemed to identify with these learning objectives, and we've found they are potentially learning objectives for a sustainability curriculum, not just a single course.

\section{CONCLUSIONS:}

With respect to community involvement, we found it important to build personal connections with potential project champions and mentors in order to get involvement. However, the role of the project champions being heavily invested in the project success was not always optimal for student learning, as it often required tradeoffs between the student experience and the project's success. The Centre for Leadership in Learning also raised concerns with scaling up community involvement without sufficient administrative resources to ensure all parties are benefiting. The role of the community mentors was generally positive, but would benefit from more structured times for involvement, including, perhaps, a specific lecture or "meet and greet" event for people to attend.

With respect to cross-faculty enrollment, we agreed that including students from multiple faculties was a core strength of the course, but opportunities exist to further build on that strength. At the top of the opportunities list are: providing more tutorial time for smaller group discussion, explicitly discussing inter-faculty tensions, and creating a clearer outline of core content.

For innovating teaching methods, the key factor seemed to be the mix of styles and formats. While we saw significant motivation from many students with respect to their projects, when specific content is required, it is probably unwise to eliminate incentives altogether.

Student projects, overall, were very successful, and they were a highlight of the students' experience in the course. Many students expressed how proud they were to have accomplished real results, and to have created something meaningful to them.

The learning objectives seemed to resonate with people, but finding language to express these values and skills remains a challenge.

Overall, the first iteration of SUSTAIN 2A03 was successful in providing a significantly unique experience for students. It provided this experience primarily by including real projects, allowing the students to feel ownership over their actions, and providing an interdisciplinary experience. The second iteration has a target enrollment of 140 students, to be offered in January 2014.

\section{Acknowledgements}

Special thanks go to the members of the SFP Planning Team including Kate Whalen, Dr. Ashish Pujari, Dr. Gail Krantzberg, Dr. Jim Quinn, Marie Vander Kloet, Dr. Michael Egan, Minha Ha, and Dr. Suzanne Mills.

Thanks also to McMaster University Faculty of Engineering, and especially Acting Dean Dr. Art Heidebrecht. 